\title{
O processo de identificação entre membros de Alcoólicos Anônimos: uma análise psicanalítica e foucaultiana de discurso
}

\author{
El proceso de identificación entre los miembros de la Asociación de Alcohólicos \\ Anónimos: interfaces entre el psicoanálisis y el análisis del discurso \\ The identification process between members of the Alcoholics Anonymous \\ brotherhood: interfaces between psychoanalysis and discourse analysis
}

\author{
Raul Max Lucas da Costa \\ Centro Universitário Dr. Leão Sampaio (UNILEÃO), Juazeiro do Norte - CE/Brasil \\ ORCID: 0000-0002-6283-4890 \\ E-mail: raulmax@leaosampaio.edu.br
}

Yan Ferreira de Alencar

Centro Universitário Dr. Leão Sampaio (UNILEÃO), Juazeiro do Norte - CE/Brasil

ORCID: 0000-0001-9935-5191

E-mail: yanfalencar@gmail.com

\section{Resumo}

O presente artigo discute a função da identificação na terapêutica do alcoolismo proposta pela Irmandade Alcoólicos Anônimos (AA). Como procedimento metodológico, realizamos um estudo bibliográfico da literatura de AA e entrevistas com dez membros de AA na cidade de Juazeiro do Norte-CE. Para a análise dos resultados, realizamos uma articulação entre a teoria psicanalítica, análise de discurso e as contribuições da filosofia foucaultiana sobre discurso e poder. Em psicanálise, a identificação é definida como o laço afetivo mais remoto que o sujeito estabelece com o objeto. Freud se vale do referido conceito em seu estudo sobre as formações grupais e das massas destacando três modos de identificação: com o pai, a sintomática e a histérica. Constatamos que para o membro de AA, a prática do programa terapêutico espiritual dos doze passos exige uma identificação sintomática com a "doença alcoólica" e com o outro membro "alcoólico". A coesão grupal da Irmandade ocorre a partir do ideal do eu de "sobriedade". A experiência dos fundadores registrada na literatura oficial da Irmandade serve como traço identificatório para os membros até hoje. Nas falas dos participantes, foi destacada a necessidade do vínculo grupal, comparado ao laço familiar, e do exercício de lideranças nos grupos, apesar da Irmandade não estabelecer líderes oficialmente. Concluímos que para os AA a terapêutica do alcoolismo equivale ao processo gradual de construção identitária do "alcoólico anônimo", cujos efeitos subjetivos são de massificação em detrimento da singularidade.
\end{abstract}

Palavras-chaves: Psicanálise; Alcoólicos Anônimos; Identificação; Alcoolismo; Subjetividade.

\section{Resumen}

Este artículo analiza el papel de la identificación en la terapia de alcoholismo propuesta por la Hermandad de Alcohólicos Anónimos (AA). Como procedimiento metodológico, realizamos un estudio bibliográfico de la literatura y entrevistas con diez miembros de AA en la ciudad de Juazeiro del Norte-CE. Para el análisis de los resultados, realizamos una articulación entre la teoría psicoanalítica y el análisis del discurso, considerando también las contribuciones foucaultianas sobre el discurso y el poder. En el psicoanálisis, la identificación se define como el vínculo afectivo más remoto que el sujeto establece con el objeto. Freud utilizó este concepto en su estudio de formaciones grupales y masas, destacando tres modos de identificación: con el padre, sintomático e histérico. Encontramos que para el miembro de AA la práctica del programa terapéutico espiritual de doce pasos requiere identificación sintomática con la "enfermedad alcohólica" y con el otro miembro "alcohólico". La cohesión grupal de la Hermandad se produce desde el ideal de la "sobriedad". La experiencia de los fundadores registrada en la literatura oficial de la Hermandad sirve como rasgos identificativos para los miembros hasta el día de hoy. En 
las declaraciones de los participantes, se destacó la necesidad de unión grupal, en comparación con los lazos familiares, y el ejercicio de los líderes en los grupos, aunque la Hermandad no estableció oficialmente líderes. Concluimos que para AA la terapia del alcoholismo es equivalente al proceso gradual de construcción de identidad del "alcohólico anónimo", cuyos efectos subjetivos son la masificación en detrimento de la singularidad.

Palabras clave: Psicoanálisis; Alcohólicos Anónimos; Identificación; Alcoholismo; Subjetividad.

\begin{abstract}
This article discusses the role of identification in the treatment of alcoholism proposed by the Brotherhood of Alcoholics Anonymous (AA). As a methodological procedure, we performed a bibliographic study of AA literature and interviews with ten AA members in the city of Juazeiro do Norte-CE. For the analysis of the results, we made an articulation between psychoanalytic theory and discourse analysis, also considering the Foucaultian contributions on discourse and power. In psychoanalysis, identification is defined as the most remote affective
\end{abstract}

bond that the subject establishes with the object. Freud uses this concept in his study of group and mass formations, highlighting three modes of identification: with the father, the symptomatic and the hysterical. We found that for the AA member, the practice of the twelvestep spiritual therapeutic program requires symptomatic identification with "alcoholic disease" and with the other "alcoholic" member. The Brotherhood's group cohesion occurs based on the self ideal of "sobriety". The founders' experience recorded in the official Brotherhood literature serves as identifying features for members to this day. In the speeches of the participants, the need for group bonding, compared to the family bond, and the exercise of leadership in the groups was highlighted, although the Brotherhood did not officially establish leaders. We conclude that for AA, the treatment of alcoholism is equivalent to the gradual process of identity construction of the "anonymous alcoholic", whose subjective effects are of massification at the expense of singularity.

Keywords: Psychoanalysis; Alcoholics Anonymous; Identification; Alcoholism; Subjectivity.

\section{Introdução}

O presente trabalho apresenta os resultados parciais do projeto de Iniciação Científica intitulado Alteridade, Sobriedade e Espiritualidade Entre Membros de Alcoólicos Anônimos em Juazeiro do Norte-CE: Um Estudo Psicanalítico, que objetivou analisar a proposta terapêutica dos Alcoólicos Anônimos (AA) para o alcoolismo através de entrevistas aos membros da Irmandade residentes na cidade de Juazeiro do Norte-CE. A relevância deste estudo consiste em discutir as particularidades dos AA enquanto instituição e as peculiaridades de sua prática doutrinária, reconhecidas mundialmente e de grande popularidade no Brasil. É notório que a proposta terapêutica dos AA dos doze passos, bem como sua organização institucional, serve de modelo estrutural para os demais grupos de ajuda mútua que lidam com a questão da dependência como os Narcóticos Anônimos (NA), Comedores Compulsivos Anônimos (CCA), Devedores Anônimos (DA), Fumantes Anônimos (FA), dentre outros. É frequente a utilização dos doze passos em instituições de tratamento da dependência química, sejam de origem privada ou não governamentais. No campo das políticas públicas de Saúde Mental, os AA são amplamente recomendados, apesar de sua proposta de tratamento via abstinência contrariar a política instituída de Redução de Danos.

Os Alcoólicos Anônimos tiveram sua origem em 1935 quando Bill Wilson e Robert Smith na cidade norte-americana de Akron, Ohio, tomaram a iniciativa de reunir um pequeno grupo de bebedores habituais e criaram a Fundação do Alcoólico, instituição destinada a realizar um tratamento alternativo ao alcoolismo a partir da abstinência e de um programa de sobriedade.

Somente em 1939, o nome Alcoólicos Anônimos surgiu a partir do lançamento do livro homônimo, conhecido entre seus membros como o "grande livro" ou ainda o "livro azul", obra que condensa as principais concepções doutrinárias e diretrizes institucionais dos AA. Neste livro os AA são apresentados como:

uma irmandade mundial de homens e mulheres voluntários, vindos de todas as camadas sociais, que se reúnem 
para alcançar e manter a sobriedade. $\mathrm{O}$ único requisito para ser membro é o desejo de parar de beber, não havendo a necessidade de pagar taxas ou mensalidades (Alcoólicos Anônimos, 2010, p. 22).

O livro apresenta a concepção de alcoolismo da Irmandade, a descrição padrão das reuniões, os relatos pessoais dos membros fundadores, as orientações aos familiares e aos empregadores, a postura agnóstica e o programa espiritual da Irmandade (Alcoólicos Anônimos, 2010).

Desde seu surgimento, uma das especificidades dos AA com relação aos tratamentos clássicos para alcoolismo reside na intenção de propor uma terapêutica desvinculada da medicina e da religião. Neste sentido, a peculiaridade de sua proposta terapêutica consiste no princípio de que somente um "alcoólico" é capaz de ouvir e ajudar outro "alcoólico", ou seja, produz uma ruptura com as discursividades especializadas enquanto detentoras do saber sobre o alcoolismo. $\mathrm{O}$ termo médico patológico "alcoolismo" surgiu em meados do século XIX como forma de nomear e disciplinar os trabalhadores pobres da espacialidade urbana dos principais centros urbanos (Carneiro, 2010). As campanhas anti-alcoólicas foram marcantes na virada dos séculos XIX para o XX através do movimento de Higiene Mental. O higienismo consistia no conjunto de intervenções sociais, políticas e ideológicas baseadas na eugenia, doutrina que defendia o aperfeiçoamento da raça humana a partir de procedimentos de purificação racial. $\mathrm{O}$ alcoolismo era considerado como uma doença social, corruptora dos corpos e da sociedade (Costa, 2015).

Neste sentido, a noção de discurso se impõe como ferramenta conceitual de destaque, possibilitando uma articulação entre psicanálise e o campo dos estudos discursivos, sem desprezar a historicidade e a política do conceito. Além da psicanálise, os estudos de Michel Foucault se revelam como importantes referências na discussão de nossa pesquisa, sobretudo, para a análise da produção dos grupos de ajuda mútua e das discursividades sobre o alcoolismo. É a partir desse autor que se amplia a discussão sobre o tratamento da dependência química, ao mesmo ponto em que se analisa a questão sobre o modo como a saúde pública tem lidado com tais grupos. Desta forma, se salienta que a produção de subjetividades em torno da preocupação com o alcoolismo, não é algo novo, surgido com o tratamento dispensado pelos AA com sua estrutura institucional e discursiva, mas que, é parte de uma relação maior do poder com as formas de vida e controle destas.

Uma novidade da Irmandade no contexto de intervenções médicas e higienistas foi de individualizar e psicologizar a "doença alcoólica". Além do reconhecimento do alcoolismo como "doença" individual, o anonimato, a crença no Poder Superior, a sobriedade diária e a vivência dos doze passos se apresentam como as principais condições de pertencimento na Irmandade (Alcoólicos Anônimos, 2010).

Encontramos na pesquisa antropológica importantes indicações sobre o processo de subjetivação promovida pela Irmandade. Vale ressaltar a primazia das ciências sociais, sobretudo, das pesquisas etnográficas, em problematizar a subjetivação entre membros de AA. De acordo com Trois (1998) o que permeia o funcionamento dos AA é a noção de grupos de iguais, ou seja, de pessoas que compartilham sofrimentos e sentimentos de fraternidade que os aproximam ao ponto de uma identificação. Para os membros dessa irmandade a noção de igualdade se apresenta como um valor, do qual eles devem compartilhar mutuamente. Através de uma representação própria, os membros preconizam a ideia de que ninguém melhor do que um alcoólico pode compreender e ajudar outro alcoólico.

Tadvald (2006) destaca que entre os membros de AA ocorre uma terapia do espelho, visto que o sujeito reconhecendo no outro uma semelhança narrativa em sua história de vida torna possível a "recuperação". Além disso, os AA possuem uma doutrina específica e um 
ritual tradicional que devem ser seguidos por todo e qualquer grupo da Irmandade. Essas normas estão preconizadas nos doze passos, doze conceitos e doze tradições apresentadas e amplamente comentadas na chamada literatura de AA: livros, livretos, revistas e informativos.

Tais considerações da pesquisa etnográfica convidam os pesquisadores do campo psicanalítico a problematizar os modos de subjetivação promovidos pelos AA e demais grupos de ajuda mútua. Considerando a relevância da alteridade como eixo fundamental da terapêutica e da organização institucional dos AA, destacamos no presente estudo a relevância da identificação, operação subjetiva central na análise freudiana sobre as formações grupais e das massas. Freud considerava a identificação como fator constituinte e inaugural do sujeito e da vida coletiva. Vale ressaltar sua premissa para o estudo dos grupos organizados e das massas: "toda psicologia individual é social" (Freud, 1921/2011, p.13).

A psicanálise pode contribuir de forma significativa para o estudo dos agrupamentos sociais que cada vez mais se utilizam dos diagnósticos como referência identitária. Dunker (2015) ressalta que o diagnóstico na contemporaneidade extrapola sua função comum da prática médica e se apresenta como baliza para formas de vida, ou seja, reestruturam e norteiam a vida dos sujeitos que buscam nomear sua condição de sofrimento e mal-estar a partir do diagnóstico.

O presente trabalho visa, portanto, analisar discursivamente $\mathrm{o}$ processo de identificação entre membros de AA no contexto do laço social contemporâneo. Como já ressaltado, a noção de discurso nos possibilitou trabalhar as fontes de nossa pesquisa, seja pelo relato oral dos membros, seja pela leitura dos referenciais básicos da literatura de AA. Buscaremos, a partir da teoria psicanalítica e de sua possível articulação sua relação com a análise de discurso (em destaque as reflexões foucaultianas), discutir as formas de tratamento das adicções na contemporaneidade em análise, considerando a
Irmandade AA como modelo para os demais grupos de ajuda mútua, revelando ser um discurso instituinte da subjetivação adicta anônima.

\section{O Conceito de Identificação em Freud e Lacan}

Para Freud (1921/2011), a identificação é a forma mais antiga de ligação afetiva com outro sujeito. A radicalidade dessa tese pode causar estranhamento, contudo reflete o árduo trabalho freudiano ao longo de sua obra sobre o referido conceito. $\mathrm{O}$ termo alemão Identifizierung remete a um processo psíquico, marcado pela ação de apropriação e exterioridade. Poderíamos assim estabelecer uma diferença marcante entre as noções de identificação e identidade, sendo a última compreendida como um referente fixo e estabelecido, enquanto a primeira indica um movimento contínuo.

Nesta perspectiva, é com o pai o primeiro laço de identificação que a criança estabelece. Uma interrogação que pode surgir sobre esta consideração freudiana é a pergunta sobre o lugar materno: não seria a mãe a primeira referência da criança? Quanto ao lugar materno, Freud esclarece que enquanto o pai serve de modelo para o menino, a mãe é objeto de uma ligação libidinal através do apoio. É notória que a leitura freudiana da primeira identificação prioriza um contexto edípico cujo referencial é o Édipo do menino. Esta busca ser como o pai. Contudo, a referência a esta primeira identificação remete à própria condição do sujeito na cultura.

Foi pela via da incorporação simbólica que Freud desvelou a origem dos laços de sociabilidade e da cultura. Em Totem e Tabu (Freud, 1912/2012) o mito do pai da horda, proposto por Freud, revela de forma mítica a precedência da identificação na constituição subjetiva. Eis o mito: O pai primevo subjuga seus filhos, proibindo-os de possuir as fêmeas da horda. Era o pai que detinha todas para si, além de exercer seu domínio de forma totalitária. Contudo, houve uma rebelião dos filhos que em busca de sair desta condição 
subalterna matam o próprio pai. $\mathrm{O}$ ato de assassínio instituiu o sentimento de culpa e a ambivalência afetiva (amor e ódio) entre os filhos que se descobrem irmãos. Como reparação, a fratria, à comunidade de irmãos, elege um referente simbólico, o totem, cuja função é assumir o lugar paterno via representação simbólica. Em torno de tal figura (animal, fenômeno natural, vegetal) se estabelece a proibição de assassinato, o tabu. Contudo, em tempos festivos e que evocam a memória, o tabu do parricídio é suspenso, permitindo a incorporação oral do totem. Freud tece essas considerações para aproximar a vida dos homens primitivos ao tempo da infância. Assim, se para o homem primitivo o gesto antropofágico possuía uma significação simbólica de incorporação de traços do outro (este é o princípio do totemismo, base da religião e do direito), na vida infantil a representação paterna servirá de referência na identificação no complexo de Édipo. A chamada dissolução do Édipo no menino e na menina é o momento crucial do estudo freudiano sobre as identificações.

A segunda forma de identificação consiste na formação dos sintomas neuróticos. Freud (1930/2010) ressalta um aspecto do Caso Dora, a situação de uma tosse contínua de sua paciente. $\mathrm{O}$ trabalho analítico lhe revelou a relação desta crise sintomática com as tosses contínuas de seu pai. Disso, é possível constatar a função da identificação sintomática como uma substituição a relação de objeto anterior, daí Freud considerar uma marca regressiva nesta forma de identificação. Essa afirmação coloca o processo identificatório como uma operação cuja função seria lidar com a falta do objeto, diante de sua inacessibilidade. É este o fato que parece ocorrer na perda do objeto de amor, ou seja, com impossibilidade de possuí-lo novamente, temos a ocorrência da identificação com os traços do objeto e sua consequente introjeção.

Como terceiro tipo de identificação, Freud nos apresenta a identificação histérica. Esta é caracterizada por sua manifestação via contágio, ou ainda, por "infecção psíquica", ocorrência comum no âmbito coletivo quando um traço específico serve de referência aos demais. É exemplar neste sentido, a suposição freudiana de uma garota residente de um pensionato que recebe uma carta de seu namorado terminado o relacionamento. Enquanto ela pranteia sua perda, todas suas colegas, via identificação histérica, põem-se também a chorar. É preciso reafirmar que essas observações de Freud residem em uma teoria das massas, logo, há na histeria um lugar diferente de uma patologia, mas, uma forma de funcionamento que existe também na relação dos grupos, salientado que essa é uma das operações que sustentam a relação com os outros (Freud, 1921/2011).

Outra característica comum nas formações grupais e de massas, que até o momento da análise freudiana não havia sido discutida pelas pesquisas sociológicas e psicológicas, é a função primordial do líder como catalisador das coletividades. Ocorre a tendência dos membros da massa a se identificarem com um traço apresentado pelo líder. Vale ressaltar que esta identificação é com um traço e não com a pessoa do líder. Freud entende que o líder nada mais é do que um sucedâneo do mítico pai da horda, fato que o levar a aproximar a massa da horda primeva, daí seu aspecto primitivo quando, por exemplo, eleva as manifestações afetivas, amor e ódio, em declínio do pensamento lógico racional.

Nesse sentido, é possível entender que a construção de um ideal do eu funciona como um substituto do líder, ou seja, em vez de uma pessoa, o que vem a nortear as coletividades é a instância do ideal do eu, que se apresenta como ideais de conduta social. Assim, o ideal do eu pode ser entendido como um modelo egóico instituído pelo laço civilizatório. Mantém uma distinção com o eu ideal, característico do narcisismo primário, que diz respeito a uma idealização do eu de cada sujeito e que tem uma formação relacionada a função da lei e da moral individual.

Até este momento da obra freudiana, o conceito de supereu não havia sido formalizado, fato ocorrido somente com seu texto O Eu e o Isso de 1923. mais adiante em o 
Mal-estar na Civilização (1930), o conceito de supereu suplanta suas referências anteriores, como a ideia de consciência moral, caracterizando-se como um imperativo moral e gerador do sentimento de culpa. Ao mesmo tempo que ordena a lógica dos objetos de afeição, ou seja, estrutura a forma como o eu encontra no outro afeto, do amor ao ódio. Com essa elaboração conceitual, a noção de ideal do eu passa a ser incluída no conceito diferente do supereu.

Freud (1930/2010) considera ainda que um sujeito pode pertencer a variados grupos e massas sociais, fato que reverbera sua tese de que toda psicologia individual é social. Situações típicas da sociabilidade como a empatia, a consciência social, grupos de fãs, o ideal político do comunismo, passam pelo crivo do conceito de identificação. É aí que Freud rompe com uma divisão existente entre a lógica de funcionamento de um sujeito com a sociedade. Uma consideração importante que responde às constantes críticas empreendidas contra a psicanálise. Noção que funciona também como basilar diante das ponderações das psicologias sociais e comunitárias. A concepção de sujeito na psicanálise não é sem uma teoria do laço social.

A contribuição de Lacan para o conceito de identificação ocorreu sobretudo com o seu nono seminário (Lacan, 2014). Ao retomar a identificação histérica definida por Freud, ele a considera diferente de uma imitação ou mesmo diferente do pensamento de que a identificação seria uma referência pura e simples a um outro ao qual nos identificamos. Para Lacan, a identificação histérica revela uma identificação ao significante. No que se refere à identificação ao traço unário (tradução lacaniana do termo Einziger Zug utilizado por Freud) esta é a que possibilita o funcionamento da cadeia significante e, consequentemente, o advento do sujeito no campo da linguagem:

... é sobre ele (traço unário) que se concentra para nós a função de indicar o lugar onde está suspensa no significante, onde está pendurada, no que concerne ao significante, a questão de sua garantia, de sua função, disso a que serve este significante, no advento da verdade. (Lacan, 2014, p.37).

O traço unário é o que torna possível o significante. Como exemplo, Lacan fala de sua observação da peça no Museu de SaintGermain: um osso de costela animal préhistórico marcado por vários traços em formato de bastões formando uma série. Especula o psicanalista francês sobre o que poderia significar para o homem primitivo tais marcações em um osso. Independente do significado exato, conclui a necessidade do tracejar para o surgimento da escrita e consequentemente do registro simbólico (Lacan, 2014).

A identificação simbólica consiste precisamente na constituição do sujeito do inconsciente, compreendido como a produção de um traço singular que se distingue ao retomarmos a diferença produzida pela cadeia significante do um a um. Com isso, enquanto Freud destaca o registro egóico através da relação do $\mathrm{Eu}$ com o Ideal do Eu para a ocorrência da identificação nas massas, Lacan ressalta a função do Outro como condição de subjetivação e do laço com os outros. Desta forma, na identificação simbólica o sujeito do inconsciente está identificado com um traço unário, fato que implica a funcionalidade do Outro como lugar dos significantes.

Interessante notar que o tema da constituição do sujeito perpassa de modo central três dos seminários lacanianos: $\underline{\mathrm{A}}$ Identificação (2014), A Angústia (2004) e os Quatros Conceitos Fundamentais da Psicanálise (1998). Destaca-se nessa tríade de seminários as elaborações teóricas sobre o sujeito e o significante junto aos conceitos de grande outro (A) e objeto a constructos conceituais importantes para a delimitação e a ligação dos registros Real, Simbólico e Imaginário.

Além da identificação simbólica calcada no significante, Lacan situa a identificação imaginária na ocasião do estádio 
do Espelho, momento constitutivo de formação do Eu através da constituição da imagem unificada do corpo. O olhar do grande Outro, enquanto marca de investimento libidinal, serve para criança como uma doação de uma imagem egóica, daí sua semelhança a um espelho. Há uma equivalência, portanto, entre a consideração freudiana sobre o narcisismo primário, momento de investimento parental na criança, e do estádio do espelho lacaniano.

Desta forma, segundo Stenner (2004) tanto a identificação imaginária quanto a identificação simbólica dependem daquilo que, fora do sujeito, lhe fornece elementos de sustentação, de um lado, de estruturação, a partir do Outro. Na identificação simbólica, a substituição repetida de um traço primeiro é o processo de recalcamento que caracteriza a formação da metáfora paterna. Na identificação imaginária, é a própria imagem refletida, desde que apoiada em uma palavra nomeadora do Outro, que fornecerá uma primeira experiência de identificação.

Em suma, Lacan diferencia a identificação imaginária da identificação simbólica como processos cruciais para a constituição do sujeito. A identificação imaginária está relacionada à formação do Eu a partir do imaginário e a identificação simbólica dá origem ao sujeito do inconsciente a partir da função do traço unário, da diferença significante e do Outro que marcam a história do sujeito (Poian, 2002). Vale ressaltar que nos últimos seminários lacanianos, o registro do Real, definido como o impossível de simbolizar, ganhará uma centralidade em suas teorizações a partir do enodamento borromeano do RSI.

\section{O poder como produção de subjetividades}

Em diálogo com os referenciais foucaultianos, podemos estabelecer uma relação com o processo de identificação com a produção de subjetividade empreendida a partir das instituições. É Foucault (1975/1996) quem abre a luz para pensar as instituições e seus discursos como produtoras de sujeitos. Quando o mesmo estabelece a transformação do poder na história, atenta para uma mudança das práticas sociais que passaram a ser condenadas e proibidas no âmbito social. Na Idade Clássica, o poder soberano era o exercício da força e do controle, ficando o poder detido nas mãos do rei. Este, era o modelo de governamentalidade, como em uma grande família, o soberano decidia quem deveria morrer e viver. Contudo, no século XIX, o advento das instituições promove uma outra lógica, a do poder disciplinar que toma o corpo como objeto a ser controlado e domesticado. Aqui, a família passa de modelo a objeto de intervenção da governamentalidade. A medicina social, passa a ditar as normas de conduta e a salubridade do espaço urbano (Diniz \& Oliveira, 2014).

Foi com a ascensão do poder disciplinar, que o controle passou a residir sobre cada cidadão, instituindo normas entre o permitido e proibido, através de uma disciplina de si, onde a vigilância ultrapassa o exercício do estado e se aloja em cada um. Assim, em torno do proibido constituiu-se uma dinâmica oculta, que deve ser vivida longe do discurso e dos olhares, nunca comentada ou trazida à luz. Nessa configuração o controle dos corpos garante a docilidade, onde é instaurada uma vigilância no laço social que se executa e mantém entre cada pessoa. (Furtado \& Camilo, 2016)

Nesse período é desvelado uma descoberta inaugural de Foucault, como afirma Diniz e Oliveira (2014) cada indivíduo faz parte de uma malha de poder, no mesmo sentido que exerce é controlado por esse, transformando assim insolúvel a dinâmica de escapar do poder. É nesse âmbito que Foucault tensiona uma nova forma de análise do social, ultrapassando a visão de um poder soberano, centrado no rei, ou mesmo a concepção marxista de uma classe detentora de um tipo de poder. Tecendo uma concepção de poder denominada microfísica, onde, no curso da história culmina em outra transformação: a biopolítica.

É como uma herança do poder disciplinar e sua absorção pelo liberalismo que ocorre o advento do biopoder, onde inaugura 
uma dinâmica de transformar em discurso o que antes era visto como proibido. Foucault $(1976 / 1988)$ demonstra que a partir da prática da confissão, a dinâmica se expande a construção de um saber científico sobre o negado. $\mathrm{O}$ que consistiu como errado deve ser dito, estudado, categorizado e tratado pela ciência e formas de fabricação da verdade. A forma de investigar essa verdade tem uma atuação específica e funda um sujeito, em particular, o moderno. A investigação deve ser feita a partir de um método rigoroso, que afaste erros e falseamentos, o discurso deve funcionar diante de uma malha, não é somente um indivíduo que tem a dinâmica de extrair a verdade dos atos funestos, segundo Maia (2011), o nascimento da população indica a gênese de uma prática de governabilidade que controla a partir de um fortalecimento de uma microfísica, onde as fronteiras diante do exercício e resistência se perdem, permitindo um contínuo fortalecimento do poder.

Com o exercício da prática de confissão cria-se a subjetividade. Com a crença de que em cada um existe uma verdade a ser desvelada e tratada, onde esse tratamento ocorre pela fala e a investigação da verdade. O sujeito do desejo é instituído. Segundo Foucault (1976/1988), é a partir da prática de confissão cristã que a culpa é estabelecida no sujeito, no mesmo sentido, a partir da concepção da verdade como oculta e a ser desvelada que se constitui o desejo. Esse desejo é compreendido como irracional, o que desalinha o sujeito da sociedade, é onde vive os atos caracterizados como inconcebíveis para a moral, assim, a sexualidade é construída no mesmo lugar do proibido, porém investigado.

Furtado e Camilo (2016) explicitam que há duas formas de expressão do biopoder, a primeira é a potencialização da docilidade dos corpos, ampliando a mesma e tornando o corpo como útil, essa tecnologia advinda da disciplina converge ao tecido social compondo uma anatomia política do corpo. A segunda expressão é a biopolítica, essa se liga ao controle da vida, regulando a natalidade, taxas de imigração, epidemias, um saber articulado que transforma o corpo vivo em uma massa a ser estudada e controlada, denominada população.

Tais práticas de saber revelam o fortalecimento do saber científico que culminou na instituição de uma dinâmica metódica de investigação e extração da verdade. Para Foucault (1976/1988) esse progresso revela um fortalecimento das formas de captura e dominação do sujeito. Sua teoria abre mão de uma concepção de luta de classe, identifica o poder constituído como uma malha de discursos, que articuladas nas práticas reais, formam dispositivos de controle, que regem sobre o saber. $\mathrm{O}$ avanço do saber científico sobre as doenças define claramente um jogo do verdadeiro e do falso, onde o falso, composto pelas práticas não aceitas socialmente, tomam validade como verdadeiro quando investigado e categorizado de forma minuciosa.

\section{Método}

Trata-se de uma pesquisa qualitativa, de campo e exploratória. Como instrumento de coleta de dados, realizamos entrevistas estruturadas com 10 membros de AA residentes na cidade de Juazeiro do Norte-CE. Todas as entrevistas foram concedidas através de Termo de consentimento Livre e Esclarecido (TCLE) e fundamentadas nas recomendações éticas da resolução 466/12 que trata da pesquisa com seres humanos. Como critérios de inclusão, buscou-se a participação de membros que tivessem experiência e conhecimento sobre o funcionamento da Irmandade. A presente pesquisa contou com a aprovação do Comitê de Ética da IES (CAAE: 49861015.0.0000.5048, Número do parecer: 1.346.008) que colaborou com a execução da pesquisa. Ao longo do artigo, os participantes da pesquisa serão identificados pela numeração de 1 a 10 . A fundamentação teórica para a análise dos resultados foi a psicanálise em suas vertentes freudiana e lacaniana e sua interface com saberes afins, sobretudo, com suas aproximações com à análise de discurso (Dunker, Paulon, \& Milán-Ramos, 2016) e privilegiando uma interlocução com o pensamento de Michel Foucault, sobretudo, suas considerações sobre os conceitos de 
discurso e poder. Apostamos no debate interdisciplinar como caminho de ampliação da discussão temática deste trabalho visando possíveis reverberações para trabalhos futuros.

\section{Resultados e Discussão}

A partir dos dados coletados e da análise das entrevistas semiestruturadas, constata-se que, para os participantes da pesquisa, a Irmandade dos AA funciona como um lugar de produção de narrativas de vida, e partilha através da fala. Assim, o momento do grupo e o pertencimento à Irmandade possuem uma função de amparo, como um Outro doador de significantes fundamentais para a identificação com a "doença" alcoolismo e com a condição de anônimo. A similitude entre os relatos de vida, marcados por um antes e depois, ou seja, o momento "da ativa" de alcoolismo inveterado e o momento de parar de beber e busca pela sobriedade. Campos (2010) chama essa semelhança entre as histórias de vida como espelhamento. Entre os membros de AA existe a concepção que os relatos de alcoolistas sempre são os mesmos (perda de emprego, problemas familiares, separações) só mudam de endereço. O tempo da sobriedade passa a ser marcado pela presentificação do "só por hoje", ou seja, uma ênfase no tempo presente entendido como técnica primordial para a abstinência alcóolica.

Além da bebida alcoólica como objeto em comum, a condição de doente alcoólico, a necessidade da crença em um Poder Superior, condição fundamental para a prática dos doze passos, entre os AA predomina a ideia da importância da convivência com outros alcoólicos. Dessa forma, podemos perceber o processo de identificação pela via sintomática, a ideia do alcoolismo como uma doença individual, e pela via histérica, a concepção de que só um alcoólico pode ajudar outro alcoólico. Para Melman (1999) há no alcoolismo uma tendência à fraternidade, pois historicamente se trata de um padecimento próprio dos proletários. A classe trabalhadora explorada pela burguesia buscou unir-se para reivindicar seus direitos. Contudo, o consumo alcoólico seria, neste sentido, uma tentativa de recuperação de um gozo usurpado pelo Outro capitalista. Esta situação corrobora com a observação lacaniana de que discurso capitalista, aquilo que foi expropriado do proletariado retorna para ele como mercadoria (Lacan, 1992). Na condição de alcoolistas a fraternidade persiste agora na formação de grupos anônimos como uma forma de fazer uma barreira ao gozo alcoolista.

Para os membros dos AA, o conhecimento da literatura oficial é uma condição importante para o reconhecimento fraterno da condição de doente alcoólico. Nas falas dos entrevistados são notórias citações de trechos do livro Alcoólicos Anônimos (2010), referência básica da Irmandade. As frases foram utilizadas para ressaltar a noção de coletividade entre os AA:

Aprendemos que precisamos admitir... (Participante 09);

Nós, alcoólicos, homens e mulheres... (Participante 10);

Uma vez terminado nosso inventário pessoal... (Participante 04);

Achamos ser bastante aconselhável... (Participante 05).

A partir dessas frases podemos perceber que a referência no plural por si só, faz com que o sujeito fique escamoteado em uma massa representada pela Irmandade dos AA. Em outras palavras, há uma perda da noção de singularidade em favor da coletividade. $\mathrm{O}$ apelo ao laço comunitário é justificado como uma forma de fortalecimento diante do perigo em comum: "Mas, há, entre nós, um companheirismo, uma amizade e uma compreensão indescritíveis e maravilhosas. Somos como passageiros de um naufrágio quando a camaradagem, a alegria e a democracia se espalham por toda parte, da terceira classe à mesa do Capitão" (Alcoólicos Anônimos, 2010, p.57).

Ao se definirem como uma irmandade, os AA qualificam seus membros todos como uma fratria. Lacan (1992) ao analisar sobre o 
mito do pai da horda estabelece que assim como o pai, nada garante aos irmãos que o são de fato, ou seja, a irmandade e a paternidade flutuam entre a incerteza da verdade. A descoberta da fratria só ocorre com o assassinato do pai primevo. No mito freudiano, o pacto entre irmãos foi a condição para o estabelecimento da função simbólica totêmica e o tabu como Lei proibitiva e ordenadora. Conforme Lacan (1998), uma consequência direta que está na origem da fraternidade é seu efeito de segregação. O laço fraterno só se estabelece como diferenciação de outros enlaces sociais.

No AA tudo é muito fervoroso, nós nos consideramos irmãos muitas vezes mais do que irmãos de sangue, até porque o irmão de sangue às vezes você tem receio de contar alguma coisa, mas para os membros do AA os relacionamentos são muito estreitos mesmo, por exemplo, eu tenho companheiros do AA que eu não passo um dia sem se falar. (Participante 03).

Um aspecto implícito da segregação promovida pelo grupo é a restrição dos laços de convívio entre os membros. As entrevistas sugerem que o vínculo com o outro alcoólico ultrapassa os limites da sala de reunião e chega às casas e aos espaços de lazer, significando para os mesmos uma nova forma de vida semelhante a uma família.

Assim, entre os participantes, foi comum a noção dos AA como uma nova família ou mesmo como suplemento da família já existente. As falas caminham sempre para uma concepção de embate com a vida antes do AA, assim como papel dentro da família biológica e a relação após o advento da nova família, em conjunto ao AA.

Na vida familiar bastante mudança. Inclusive hoje lá em casa tudo é eu. Antigamente ninguém precisava de mim pra nada. (hoje ela que assume a responsabilidade da mãe doente). A confiança da família tá muito boa, adquiriu um processo de confiança muito bom. (Participante 01).
A nova família fraterna dos AA, serve, portanto, como via de reconstrução para a família de sangue. Com estabelecimento de uma identificação sintomática e histérica entre os membros, a vida anterior ao grupo é significada como uma antiga forma de vida adoecida e destrutiva. Em algumas falas dos entrevistados, o alcoolismo é associado às gerações anteriores, sugerindo uma perspectiva da "doença alcoólica como hereditária". Freud (1921/2011) concebe o fortalecimento de um dado grupo organizado, justamente quando este inicia sua união a partir dos afetos. No caso em específico, a Fraternidade dos AA se vale do combate a um inimigo comum: o álcool. Romper com o aspecto transgeracional do alcoolismo passa a ser uma das metas do novo membro:
Na minha casa é o que tem mais problema, na minha casa é uma coisa que não, não, não sai, se é uma coisa que tem na minha família é esse problema de alcoolismo. (Participante 09).

Outro aspecto relevante no engajamento da Irmandade é a funcionalidade da crença. Esta, para os membros do grupo, parece se apresentar de forma diferenciada, porém predomina a concepção de Deus, no sentido do cristão. Esse fator é evidente na dependência subjetiva desses membros ao grupo e a ação do Poder Superior. Conforme um dos entrevistados:

...muitas coisas que eu não queria passar eu passei, problemas com minha família aí chegou a mensagem dada por Deus, que nós temos uma dádiva, então nós chegamos em alcoólicos anônimos, então hoje eu faço a minha sobriedade pelos princípios de AA que é a nossa bíblia, a bíblia de $A A$ diz que somos realmente fracassado para quem segue os caminhos de AA, aqueles que não querem é quem não tem a 
capacidade e a honestidade de viver em AA. (Participante 09).

A noção de Poder Superior se apresenta em todas as falas como uma alteridade fundamental para a funcionalidade do tratamento do alcoolismo e para a constituição do laço com os outros membros dos AA. Tal alteridade maior indica uma posição subjetiva de alienação ao Outro. O Poder Superior, de forma recorrente nomeado como Deus, é um Outro de poder, que tudo sabe e tudo é capaz de realizar. A prática dos doze passos exige uma entre espiritual a este Outro e deixá-lo conduzir uma transformação subjetiva.

A constante referência ao significante "alcoólico" estabelece uma identificação sintomática com a posição de dependente alcoólico. O significante "alcoólico" faz cadeia com o significante "anônimo". Tal fato repercute como uma forma de nomeação de uma situação anterior de sofrimento psíquico. De acordo com um dos entrevistados:

Eu passei a sofrer as consequências sem conhecimento, né? Depois descobri que existia o A.A que me tornava alcoólatra e eu aceitei que eu sou alcoólatra. (Participante 09).

Vemos aqui o exercício da função diagnóstica (Dunker, 2015) como uma tentativa de nomear o mal-estar. O diagnóstico alcoolismo produz uma significação retroativa, um saber sobre a condição adicta. Tal reconhecimento de si como doente se apresenta como o primeiro do programa espiritual dos doze passos.

A identificação desempenha ainda um processo de configuração do próprio Eu a partir da semelhança que se estabelece com o outro e toma-o assim como modelo, observando que essa identificação com esse outro tem uma grande eficácia para a coesão e continuidade do objetivo que é almejado pelo grupo: a manutenção da sobriedade:

A gente costuma dizer que é pássaro de uma asa só, só voa com o outro porque a identificação é total, porque às vezes a pessoa tá em cabeceira de mesa e ele ta contando o que aconteceu com ele no alcoolismo e é quase igual ao que aconteceu comigo, porque o bebedor ele causa quase sempre os mesmos problemas. É palhaço, às vezes gasta o que não tem, deixa a família passando fome e tal, então só muda mesmo o ator, mas a história... é um se identificando com o outro. (Participante 01).

Nesse sentido, o padrinho de AA se apresenta como figura constante de incentivo $\mathrm{e}$ referência.

Existe uma história, um problema que eu tenho comigo que eu não posso contar aqui. Então tenho que ter um padrinho de confiança que é pra mim contar o que acontece comigo dentro de um quarto lá em casa até na calçada. Eu não tou dizendo aqui, que eu não posso contar tudo não, eu não conto, eu tenho aquele padrinho que é um padrinho de mais confiança que eu posso sair aqui agora e ligar pra ele pra ele ir lá em casa se tou precisando de uma ajuda e assim assim, eu tou passando assim e assim... E esse bate papo dura horas e horas. (Participante $05)$

Assemelha-se, portanto, com a relação de manutenção de um grupo com a identificação aos traços de um líder, ao mesmo tempo em que ocorre a introjeção do significante "alcoolista". Este duplo funcionamento coloca uma adesão do sujeito que busca se proteger da angústia, do vício do álcool. É aí que a sobriedade encontra subsídio para funcionar, mas, ao mesmo tempo revela um aprisionamento desse sujeito a lógica de funcionamento do grupo, ou seja, é preciso que o significante cole e ordene a cadeia, para que o ato do uso do álcool não se repita.

Sabot (2017) evidencia um tipo particular de dispositivo de controle e exercício 
do poder disciplinar, denominado por Foucault como exame, constituído por um sistema punitivo cotidiano assentado em um saber e registro que busca categorizar e definir formas de comportamento e biologia. Tal mecanismo se exemplifica nas ditas instituições de sequestro, as quais são hospitais psiquiátricos, prisões, fábricas e escolas. O autor identifica ainda em Foucault a dinâmica das prisões como um para além da instituição, defendendo a concepção de que a matriz de controle prisional, associada à culpabilidade e assunção de um crime se alastra às outras instituições citadas.

Candiotto (2020) enfatiza que as instituições de sequestro são responsáveis pela sujeição a uma subjetividade particular, onde o controle e disciplina dos corpos se tornam regras para construção de uma vontade obediente às normas. O panóptico moderno, como definido pelo autor, transforma a tríade da vigilância, controle e correção como a única forma de se colocar diante do outro e de si. Logo, esse processo de sujeição se formaliza como o natural e indissociável.

Tal forma de sujeição se exemplifica na fala de alguns entrevistados, quando concebem o alcoolismo como uma doença, com o aval da Organização Mundial de Saúde (OMS) e da doutrina dos AA:

Mas eu tinha que entender também que eu sou um doente alcoólico, eu sou uma pessoa que nunca mais eu vou poder beber porque o alcoolismo é reconhecido pela organização mundial de saúde como uma doença que não tem cura, então se não tem cura eu nunca mais vou poder beber novamente. (Participante 03).

A prática do alcoolismo é controlada a partir dessa perspectiva, uma doença incurável, logo, que impede o contínuo consumo. Revelase que o ato de beber desempenha um papel de prazer, como explicitado pelo entrevistado:

Eu senti que eu tinha encontrado uma grande coisa na minha vida que era o álcool ai desde o início minha vida bebendo então a minha adesão ao álcool foi muito rápida, porque rapidamente eu fiquei muito dependente da bebida, assim pra me divertir, sempre que eu pensava em me divertir eu pensava primeiro em beber. (Participante 03).

Foucault (1976/1988) discute que a dinâmica do prazer é o que escapa às normatizações e ao poder. Para o autor, o prazer sexual detém uma faísca de resistência diante das práticas discursivas, visto que essas não conseguem categorizar totalmente. Uma tentativa do controle do prazer é escamoteá-lo ao dito, logo, constituir uma narrativa sobre o prazer. O que se revela nas entrevistas é que os AA lida com a questão do prazer não só na tentativa de colocar em discurso, mas, que o instaura como o não-permitido. Para sustentar essa proibição justificam a categorização do sujeito como alcoólico, logo, impedido de beber.

Não sabia que alcoolismo era uma doença, eu acreditava que eu era o que as pessoas me diziam, que era uma pessoa sem vergonha, era isso que eu pensava, não tinha conhecimento que alcoolismo era doença e em relação aos alcoólicos anônimos eu nunca fiz assim nem um julgamento até porque eu não sabia a respeito do $A A$. (Participante 03 ).

Tal concepção de proibição é presente em todas as falas dos entrevistados, revelando uma dinâmica que faz o grupo funcionar, mas, ao mesmo tempo, que une, também separa. O que escapa nesse discurso são as recaídas, em alguns mais frequente do que em outros. Corrobora com a visão de Foucault (1976/1988) sobre o prazer como resistência à normatização do poder. É esse jogo de união e separação que permite ao biopoder de se reinventar, sempre na tentativa de captura e fundação das subjetividades, a tentativa de tudo dizer acompanhado da impossibilidade da 
totalidade da significação é o que move as engrenagens do poder.

\section{Considerações finais}

A terapêutica do alcoolismo promovida pelos AA privilegia a identificação na construção discursiva do alcoolismo como "doença". O enunciado "sou alcoolista", implica além de uma patologização da subjetividade, na criação de uma identidade marcada por sua negatividade, se considerarmos os ideais do $\mathrm{Eu}$ da contemporaneidade fortemente caracterizados pela produtividade e alto desempenho. Apesar do conceito de identidade, não pertencer ao arcabouço teórico psicanalítico, à invocamos aqui por sua conotação de fixidez e restrição, ao contrário da identificação que remete ao movimento e à fluidez das relações. Tanto na literatura oficial dos AA como nas entrevistas, os significantes "alcoólico" e "anônimo" figuram como centrais na forma de vida orientada pela Irmandade.

Dentre as fontes da identificação presentes no texto freudiano, vimos operar nos AA à simultaneidade da identificação sintomática e à histérica. Esta última, no tocante ao modo de estruturação institucional, sempre ressaltando à cooperação, à unidade e à horizontalidade como ideais a serem seguidos. Por estas vias identificatórias, fica notório para os pesquisadores como $\mathrm{o}$ processo de identificação se configura como o limiar entre $\mathrm{o}$ individual e o social.

Com isso, podemos notar o quanto importante é o pertencimento grupal, seja em sua dimensão mínima, à presença nas reuniões quanto ao engajamento em uma instituição mundial. Neste contexto, se identificar como parte integrante daquele grupo é o fator primordial, sem o qual não há tratamento. Os membros sempre se referiram ao grupo como uma família, evidenciando que seus laços de sociabilidade são restritos ao cotidiano da Irmandade. A condição de "alcoólico" promove assim uma segregação social, haja vista à restrição vivida pelos membros de frequentarem espaços de lazer e eventos festivos onde se consomem bebidas alcoólicas.

É evidente que a Irmandade instaura um novo modo de subjetivação adicta, ou seja, à do dependente ao objeto, essa atravessada pelos preceitos institucionais que promovem um apagamento da experiência de singularidade. O tratamento ofertado culmina sempre em sujeitos que são convocados a permanecerem ligados pelo resto de sua vida à instituição. Enxergar esse fato pela psicanálise abre uma perspectiva importante na sobriedade desses sujeitos, existe uma fragilidade na mesma, visto que, o sentido é sempre algo que vacila e não dá conta da angústia. Os sujeitos permanecem sóbrios enquanto permanecem sempre verbalizando que são "alcoólicos" e pertencentes aos AA. Lacan em seu ensino sempre fez referência a incapacidade do sentido funcionar como um objeto que aplacasse a angústia, é nesse caráter, que o álcool, visto pelos membros da Irmandade, como um objeto que funcionasse para diminuir a angústia, sempre retorna mesmo com o discurso da irmandade. Esta incapacidade do sentido total remete à marca de repetição na discursividade dos AA, seja na literatura como na fala de seus membros.

Os jargões e a constante rememoração dos doze passos nos textos da chamada literatura doam aos AA um aspecto de grupo religioso. O pragmatismo e a ritualística da Irmandade, apesar de sua declarada posição agnóstica, induz à presença da matriz religiosa para o tratamento do alcoolismo, buscando dar sentido e direção à vida dos sujeitos alcoólicos. $\mathrm{Na}$ fala dos entrevistados, a necessidade de eleger um Poder Superior se apresenta como um imperativo fundamental para o constante e infindável processo de recuperação. Importante ressaltar que a sobriedade é o principal ideal do Eu que norteia e organiza a grupalidade entre os membros da Irmandade, fazendo uma função lógica como à do líder descrito por Freud.

No tocante à prática discursiva, as contribuições de Michel Foucault (1976/1988) permitem revelar que essa forma de subjetivação empreendida pelo AA pode ser 
incluída em um dispositivo de controle do biopoder, como forma de manutenção da problemática do prazer. Desse fato, percebe-se que o tratamento ao alcoolismo, tanto defendido pelas instituições de saúde, culminam na captura do indivíduo e sua formação discursiva. Logo, os AA não são exceção à regra, muito menos uma nova forma de enxergar a problemática das drogas, na verdade, essa faz parte de uma estratégia de controle.

Dessa forma, conclui-se que os membros da irmandade Alcoólicos Anônimos procuram uma forma de aplacar a angústia que o álcool parece momentaneamente suprir, mas, o sentido dado por esses sujeitos é sempre vacilante e as recaídas são esperadas e acolhidas pela instituição. Embora a irmandade se ofereça como um tratamento à dependência química, pode-se afirmar que outra dependência é criada à instituição e seus preceitos, em outras palavras, os membros são a-sujeitados a irmandade e funciona como membros vitalícios.

Portanto, as visões da psicanálise e de Foucault encontram-se em alternância na leitura da discursividade sobre o tratamento do alcoolismo, visto que, a primeira identifica como ocorre a função da identificação dos sujeitos entre si e ao significante "alcoólico", assim, abre a discussão sobre a fundação de subjetividades. A resposta a esse questionamento é encontrada na obra de Foucault, onde enriquece a noção, permitindo elucidar o questionamento e mesmo abranger a forma do tratamento dos vícios na modernidade. A pequena aproximação estendida neste trabalho exibe a dinâmica do tratamento do alcoolismo e as constantes recaídas, assim como, ao que resiste, como angústia, dentro da configuração moderna do sujeito.

\section{Referências}

Alcoólicos Anônimos. (2010). Alcoólicos Anônimos: a história de como milhares de homens e mulheres se recuperaram do alcoolismo. São Paulo: Centro de Distribuição de Literatura AA para o Brasil. Candiotto, C. (2020). Sujeição, Subjetivação e Migração: Reconfigurações da Governamentalidade Biopolítica. Kriterion: Revista de Filosofia, 61(146), 319-338. doi: 10.1590/0100-512x2020n14603cc

Campos, E.A. de. (2010). "Nosso remédio é a palavra": uma etnografia sobre o modelo terapêutico de Alcoólicos Anônimos. Rio de Janeiro: Editora FIOCRUZ.

Carneiro, H. (2010). Bebida, Abstinência e Temperança: antiga e moderna. São Paulo: Editora Senac São Paulo.

Costa, R. M. L. da. (2015). Trabalhadores, Boêmios, Ébrios e Alcoólatras: tensões sociais no consumo de bebidas alcoólicas em Fortaleza (1915-1935). Fortaleza: Editora UFC.

Diniz, F. R. A., \& Oliveira, A. A. D. (2014). Foucault: do poder disciplinar ao biopoder. Scientia, 2(3), 143-158. Recuperado de https://flucianofeijao.com.br/novo/scientiaedicao-anterior-2/

Dunker, C. I. L. (2015). Mal-estar, Sofrimento e Sintoma: uma psicopatologia do Brasil entre muros. São Paulo: Editora Boitempo.

Dunker, C. I. L, Paulon, C. P, \& MílanRamos, J. G. (2016). Análise Psicanalítica de Discurso: perspectivas lacanianas. São Paulo: Estação das Letras e das Cores.

Furtado, R. N., \& Camilo, J. A. O. (2016). O conceito de biopoder no pensamento de Michel Foucault. Revista Subjetividades, 16(3), 34-44. doi: 10.5020/23590777.16.3.34-44

Foucault, M. (1996). Vigiar e Punir: história da violência nas prisões. Petrópolis-RJ: Vozes. (Obra original publicada em 1975). Foucault, M. (1988). História da sexualidade I: A vontade de saber (M. T. C. Albuquerque \& J. A. G. Albuquerque, Trad.). Rio de Janeiro: Edições Graal. (Obra original publicada em 1976)

Freud, S. (2010). O mal-estar na civilização, novas conferências introdutórias à psicanálise e outros textos (1930/1936), (P. C. de Souza, Trad). São Paulo: Companhia 
das Letras. (Obra original publicada em 1930).

Freud, S. (2011). Psicologia das massas e análise do eu e outros textos (1920-1923), (P. C. de Souza, Trad.). São Paulo: Companhia das Letras. (Obra original publicada em 1921).

Freud, S. (2012). Totem e tabu, contribuição a história do movimento psicanalítico e outros textos. (1912-1914), (P. C. de Souza, Trad.). São Paulo: Companhia das Letras. (Obra original publicada em 1912).

Lacan, J. (1992). O Seminário: livro 17: O avesso da Psicanálise. Rio de Janeiro: Jorge Zahar Editora.

Lacan, J. (2014). A Identificação. Recife: Centro de Estudos Freudianos do Recife.

Maia, A. (2011). Do biopoder à governamentalidade: sobre a trajetória da genealogia do poder. Currículo sem fronteiras, 11(1), 54-71. Recuperado de http://www.curriculosemfronteiras.org/vol1 1iss1articles/maia.htm

Melman, C. (1999). Alcoolismo, Delinquência e Toxicomania: uma outra forma de gozar. São Paulo: Editora Escuta.
Poian, C. (2002). Os novos caminhos da identificação. Caderno de Psicanálise, 24(15): 77-86.

Sabot, P. (2017). O que é uma sociedade disciplinar? Gênese e atualidade de um conceito, a partir de Vigiar e Punir. Dois Pontos, 14(1), 15-27. doi: 10.5380/dp.v14i1.56536

Stenner, A. da S. (2004). A Identificação e a Constituição do Sujeito. Psicologia, Ciência e Profissão. (2):54-59.

Tadvald, M. (2006). Serenos, Corajosos e Sábios: a plataforma terapêutica dos Alcoólicos Anônimos e de seus participantes através do olhar antropológico (Dissertação de mestrado). Universidade Federal do Rio Grande do Sul - UFRGS, Porto Alegre, Rio Grande do Sul, Brasil.

Trois, J. F. de M. (1998). A cura pelo espelho: uma leitura antropológica do dispositivo terapêutico dos grupos de auto-ajuda de Neuróticos Anônimos (Dissertação de mestrado).Universidade Federal do Rio Grande do Sul - UFRGS, Porto Alegre, Rio Grande do Sul, Brasil.

\section{Dados sobre as autoras:}

- Raul Max Lucas da Costa: Psicanalista, membro do Aleph - Escola de Psicanálise. Mestre em História Social pela Universidade Federal do Ceará- UFC. Doutor em Psicologia pela Universidade de Fortaleza - UNIFOR. Professor do curso de Psicologia do Centro Universitário Dr. Leão Sampaio - UNILEÃO.

- Yan Ferreira de Alencar: Psicanalista. Graduado em Psicologia pelo Centro Universitário Leão Sampaio. Membro do projeto Cartografias de Subjetividades na Universidade Federal do Cariri.

\section{Agências de fomento:}

- $\quad$ Programa de Iniciação Científica do Centro Universitário Dr. Leão Sampaio.

\footnotetext{
Declaração de Direito Autoral

A submissão de originais para este periódico implica na transferência, pelos autores, dos direitos de publicação impressa e digital. Os direitos autorais para os artigos publicados são do autor, com direitos do periódico sobre a primeira publicação. Os autores somente poderão utilizar os mesmos resultados em outras publicações indicando claramente este periódico como o meio da publicação original. Em virtude de sermos um periódico de acesso aberto, permite-se o uso gratuito dos artigos em aplicações educacionais e científicas desde que citada a fonte conforme a licença CC-BY da Creative Commons.
} 